\title{
Assessment of GPS radiosonde descent data
}

\author{
M. Venkat Ratnam ${ }^{1}$, N. Pravallika ${ }^{2}$, S. Ravindra Babu ${ }^{3}$, G. Basha ${ }^{4}$, M. Pramitha ${ }^{1}$, and B. V. Krishna Murthy ${ }^{5}$ \\ ${ }^{1}$ National Atmospheric Research Laboratory, Gadanki, India \\ ${ }^{2}$ Sri Venkateswara University, Tirupati, India \\ ${ }^{3}$ Jawaharlal Nehru Technology University, Hyderabad, India \\ ${ }^{4}$ SRM University, Chennai, India \\ ${ }^{5}$ B1, Ceebros, 47/20, 3rd Main Road, Chennai, India
}

Correspondence to: M. Venkat Ratnam (vratnam@narl.gov.in)

Received: 7 November 2013 - Published in Atmos. Meas. Tech. Discuss.: 3 December 2013

Revised: 17 February 2014 - Accepted: 27 February 2014 - Published: 16 April 2014

\begin{abstract}
Radiosondes are widely used to obtain basic meteorological parameters such as pressure $(P)$, temperature $(T)$, relative humidity $(\mathrm{RH})$ and horizontal winds during the balloon ascent up to the altitude of balloon burst, usually $\sim 32-$ $35 \mathrm{~km}$. Data from the radiosondes released from Gadanki $\left(13.5^{\circ} \mathrm{N}, 79.2^{\circ} \mathrm{E}\right)$, a tropical station in India, have been collected during the ascent and during the descent as well without attaching any parachute or its equivalent since the year 2008. In the present study an attempt has been made to characterize the radiosonde descent data with the main objective of exploring its usefulness and reliability for scientific purposes. We compared the data obtained during ascent and descent phases of the same sounding. The mean differences in $T, \mathrm{RH}$ and horizontal winds between ascent and descent data are found to be small and are sometimes even within the uncertainty of the measurements and/or expected diurnal variation itself. The very good consistency observed between the ascent and the descent data shows that one more profile of the meteorological parameters can be constructed within $3 \mathrm{~h}$ of time of balloon launch practically at no additional cost. Further checks are done by utilizing the 3-hourly radiosonde observations collected during the Tropical Tropopause Dynamics campaigns conducted at Gadanki. In the process of checking the consistency between the radiosonde ascent and descent data, several new findings are arrived at and are reported in this study. In general, it has taken more than half an hour for the balloon to reach the ground from the burst altitude. It is also observed that the fall velocity is close to $10 \mathrm{~m} \mathrm{~s}^{-1}$ near the surface. Finally, it is suggested to record the observations also when the balloon is descending as this information is useful for scientific purposes.
\end{abstract}

\section{Introduction}

Measurements of different meteorological parameters such as pressure $(P)$, temperature $(T)$, relative humidity $(\mathrm{RH})$ and horizontal winds are very important for forecasting the weather and for studying the thermal and dynamical state of the atmosphere. Several efforts are made to probe the atmosphere using different in situ and remote sensing techniques. In the in situ measurements, the sensors are normally located in the instruments carried aloft in aircraft and rockets or as radiosondes if vertical structure is needed. The instrument intended to be carried by a balloon through the atmosphere is equipped with devices to measure one or several meteorological variables ( $P, T, \mathrm{RH}$, winds, etc.), and is provided with a radio transmitter for sending this information to the observing station. Originally named a radio-meteor graph, the instrument is now referred to as a radiosonde, a name apparently derived by Robert Bureau from a combination of the words "radio" for the onboard radio transmitter and "sonde", which is messenger from old English.

The earliest radio soundings were done in the late 1920s and 1930s by V. Väisälä. However, archived data generally begin in the 1940 s, with significant expansion of the network at the time of the International Geophysical Year (1957-1958). Currently, the global radiosonde network includes about 1300 upper-air stations (http://www. wmo.int/pages/prog/www/OSY/Gos-components.html), and about two-thirds of these conduct the experiment twice daily (at 00:00 and 12:00 UTC) (Durre, 2006; Immler et al., 2010). The network is predominantly land-based and favors the Northern Hemisphere as it is covered mostly by land. 
Measurements at every $12 \mathrm{~h}$ from these locations may be enough to define the large-scale weather patterns, though not sufficient to define small-scale weather events. However, for many purposes the balloon sounding is an ideal research tool. In addition, some radiosondes are flown with sensing systems for atmospheric constituents, such as ozone concentration and radioactivity. The ranges of meteorological parameters are 1050 to $5 \mathrm{hPa}$ for $P, 50$ to $-90^{\circ} \mathrm{C}$ for $T$ and 100 to 1 percent for RH, with the systems being able to sustain continuous reliable operation even when operating in heavy rain or in the vicinity of thunderstorms or in severe icing conditions. See detailed review on the quality of the radiosonde measurements worldwide by Durre et al. (2006) and the World Meteorological Organization inter-comparison report of highquality radiosonde systems (WMO, 2011). Note that Sodell et al. (2004) employed Aerosonde, which is a programmable robotic aircraft developed mainly for use over remote and inaccessible regions (like oceans), for meteorological observations and compared them with simultaneous radiosonde observations and found good agreement between the two. However, Aerosonde has not been much in use probably due to the complexities involved, limitation on measurement ceiling and cost factor.

As mentioned earlier, in general, radiosondes are widely used to obtain major meteorological parameters up to an altitude of balloon burst, usually $\sim 32-35 \mathrm{~km}$. It costs up to USD 200 per each launch including the cost of balloon, gas, manpower, etc. However, many observations worldwide are not done up to altitudes higher than the tropopause (Durre et al., 2006) or about $25 \mathrm{~km}$ because of the higher cost of the balloons and gas necessary to lift the equipment to the low pressures. In general, across the world data are collected only during ascent of balloons, and once a balloon bursts the data collection is terminated. There may be several reasons for this including the thought of sensing different air masses between the ascent and the descent (due to balloon drifts) sensor response time (descent rate is faster than the ascent rate). Chen et al. (2013) employed a light-weight hard ball as a parachute to the descending radiosonde to deduce vertical air motions at altitudes below $\sim 12 \mathrm{~km}$. In the present study we obtained the meteorological data from the descending radiosonde without attaching any parachute or its equivalent and explored the usefulness and reliability of the data during the descent. To the best of our knowledge there was no such study earlier. The ascent and descent data have been obtained from the radiosondes released (without any parachute or equivalent) from Gadanki $\left(13.5^{\circ} \mathrm{N}, 79.2^{\circ} \mathrm{E}\right)$, a tropical station in India since the year 2008 for this purpose. The results of this study are presented in this communication.

\section{Database}

High-resolution GPS radiosonde (Meisei, Japan, make RD$06 \mathrm{G})$ balloons were launched almost regularly from Gadanki during January 2008 to December 2011 around 17:30 IST $(\mathrm{IST}=\mathrm{UT}+05: 30 \mathrm{~h})$. The weight of the sonde is $150 \mathrm{~g}$ and is attached to a $600 \mathrm{~g}$ Totex balloon. The dimensions of the sonde are $98(\mathrm{~W}) \times 155(\mathrm{H}) \times 88(\mathrm{D}) \mathrm{mm}$. Note that no parachute is attached to the balloons launched from Gadanki. About 1461 profiles of $P, T, \mathrm{RH}$, and horizontal winds reaching an average altitude of $\sim 30 \mathrm{~km}$ were obtained in different seasons during the aforementioned period. The data of the atmospheric parameters were collected at sampling intervals of $1 \mathrm{~s}$ corresponding to an altitude interval of 5-6 m. The accuracy of altitude measurement is $5 \mathrm{~m}(\mathrm{rms})$ between $1000 \mathrm{hPa}$ to $3 \mathrm{hPa}$. The original response time of the temperature (negative temperature coefficient thermistor) sensor varies from $0.5 \mathrm{~s}$ or less at $1000 \mathrm{hPa}$ to $10 \mathrm{~s}$ at $10 \mathrm{hPa}$ though the data are recorded for every $1 \mathrm{~s}$. The response time for the humidity (capacitance based thin polymer) is $0.5 \mathrm{~s}$ or less at $1000 \mathrm{hPa}$ and $25^{\circ} \mathrm{C}$ (Meisei Ltd., Japan) and goes to $10 \mathrm{~s}$ for a step change from $11 \%$ to $93 \% \mathrm{RH}$, respectively. The balloon burst altitude of all the radiosondes launched during 1 January 2008 to 31 December 2011 is shown in Fig. 1a, and the minimum altitude reached during descent is also superimposed in the same panel. The number of profiles reaching different altitudes in the ascent and the descent is shown in Fig. 1b, and the statistics in different seasons is given in Table 1 . Note that the minimum altitude in the descent is not zero (ground) owing to the failure of the radio communication at altitudes close to the ground due to surrounding complex terrain of Gadanki location. The minimum altitude has a seasonal dependence as can be seen from the table. During the monsoon season, the profiles reaching down close to the ground is less than during the other seasons due to blocking of the hills located in the southwest side. Note that radiosonde will drift in the southwestern side of Gadanki during this season due to the prevailing winds in that direction.

As mentioned earlier, there were 1461 soundings - out of which 537 soundings were later eliminated due to nonavailability of usable descent data mainly because of very short duration of the data for a meaningful assessment. The descent data of radiosondes were not recorded initially in the starting year 2008. Thus, there are 924 soundings in total available for the present study; when they are segregated into seasons, the number of soundings is 256, 234, 218, and 216 during winter, pre-monsoon, monsoon, and post-monsoon seasons, respectively. Out of the 924 balloons, only 14 balloons reached less than $16 \mathrm{~km}$ altitude in ascent. About $98.2 \%$ of the balloons reached the altitude of tropical tropopause (around $16 \mathrm{~km}$ ) and $92.6 \%$ and $85.5 \%$ reached the altitude of greater than $20 \mathrm{~km}$ and $25 \mathrm{~km}$, respectively. Note that higher altitudes are attained over our station by using quality balloons (Totex, Japan) unlike in the worldwide radiosonde statistics reported by Durre et al. (2006), which reveals that most of the radiosondes terminate near the tropopause. The number of balloons reaching close to the surface $(0-1 \mathrm{~km})$ in descent is highest in the pre-monsoon season and least in the monsoon season. From Table 1 it is 

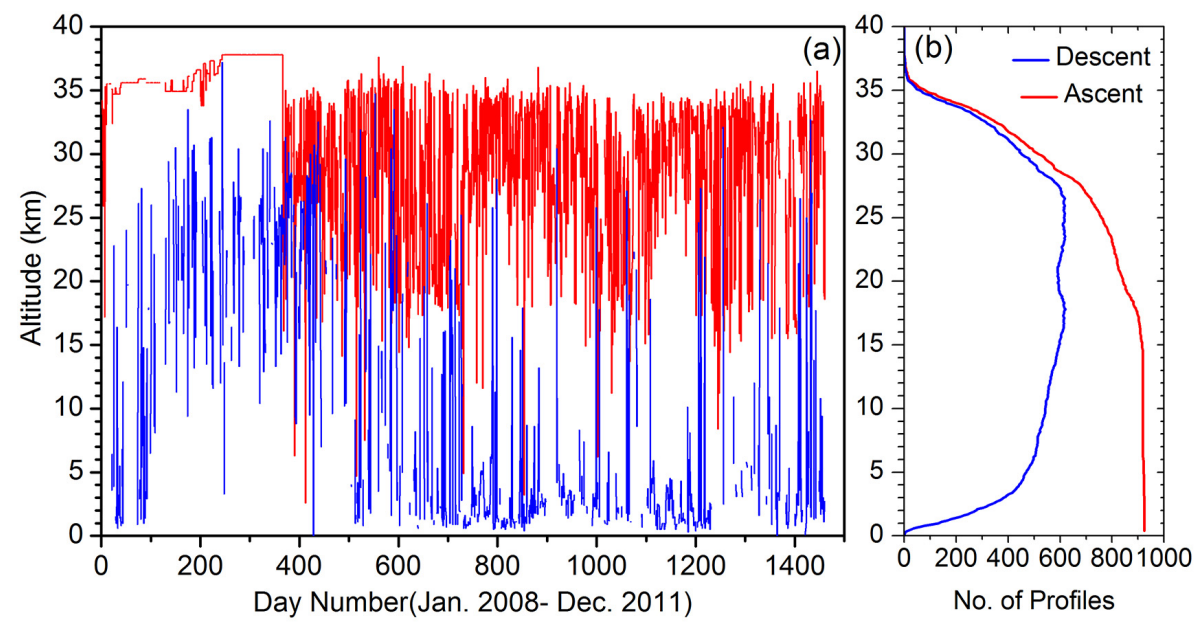

Fig. 1. (a) Balloon burst altitude (ascent) and the minimum altitude (in descent) of all the radiosondes launched from Gadanki during 1 January 2008 to 31 December 2011. (b) Number of balloons reaching maximum and minimum altitudes while in ascent and in descent, respectively.

Table 1. Statistics of number of balloons reaching the minimum and maximum altitudes while descending and ascending time, respectively, during different seasons together with statistics of 4 years. The values presented in the brackets are the percentages.

\begin{tabular}{llllll}
\hline Minimum altitude & Winter (256) & Pre-monsoon (234) & Monsoon (218) & Post-monsoon (216) & 4 years (924) \\
\hline $0-1 \mathrm{~km}$ & $33(12.89 \%)$ & $49(20.94 \%)$ & $2(0.92 \%)$ & $24(11.11 \%)$ & $108(11.69 \%)$ \\
$1-2 \mathrm{~km}$ & $79(30.86 \%)$ & $110(47.01 \%)$ & $13(5.96 \%)$ & $66(30.55 \%)$ & $268(29 \%)$ \\
$2-3 \mathrm{~km}$ & $108(42.19 \%)$ & $130(55.56 \%)$ & $45(20.64 \%)$ & $94(43.52 \%)$ & $377(40.80 \%)$ \\
$3-4 \mathrm{~km}$ & $126(49.22 \%)$ & $137(58.55 \%)$ & $69(31.65 \%)$ & $108(50.0 \%)$ & $440(47.62 \%)$ \\
$4-5 \mathrm{~km}$ & $131(51.17 \%)$ & $140(59.83 \%)$ & $78(35.78 \%)$ & $114(52.78 \%)$ & $465(50.32 \%)$ \\
$5-10 \mathrm{~km}$ & $149(58.20 \%)$ & $158(67.52 \%)$ & $106(48.62 \%)$ & $129(59.72 \%)$ & $542(58.66 \%)$ \\
\hline Maximum altitude & & & & \\
\hline $10-15 \mathrm{~km}$ & $255(99.61 \%)$ & $231(98.72 \%)$ & $218(100 \%)$ & $214(99.07 \%)$ & $918(99.35 \%)$ \\
$15-20 \mathrm{~km}$ & $253(98.83 \%)$ & $231(98.72 \%)$ & $218(100 \%)$ & $214(99.07 \%)$ & $916(99.13 \%)$ \\
$20-25 \mathrm{~km}$ & $242(94.53 \%)$ & $223(95.30 \%)$ & $208(95.41 \%)$ & $168(77.77 \%)$ & $841(91.02 \%)$ \\
$25-30 \mathrm{~km}$ & $224(87.5 \%)$ & $209(89.32 \%)$ & $186(85.32 \%)$ & $138(63.89 \%)$ & $757(81.93 \%)$ \\
$30-35 \mathrm{~km}$ & $136(53.12 \%)$ & $152(64.96 \%)$ & $131(60.09 \%)$ & $9(41.20 \%)$ & $508(54.98 \%)$ \\
$35-40 \mathrm{~km}$ & $11(4.30 \%)$ & $7(2.99 \%)$ & $41(18.81 \%)$ & $14(6.48 \%)$ & $73(7.90 \%)$ \\
\hline
\end{tabular}

clear that more than $50 \%$ of balloons reached $5 \mathrm{~km}$ (in descent) in all the seasons. In contrast to this, the number of balloons reaching the maximum altitude is lowest in the premonsoon season and highest in the monsoon season.

\section{Background conditions}

\subsection{Topographical conditions}

Before going into the details of the results, the topography and background atmospheric conditions over the study region are presented, which will be useful in interpreting the observed results. The station Gadanki is in a rural environment located about $120 \mathrm{~km}$ northwest of Chennai (Madras) on the east coast of the southern Indian peninsula. The location and topography of the Indian subcontinent and more detailed topography of Gadanki are shown in Basha and Ratnam (2009). Note that this station is surrounded by hills with a maximum altitude of $350-400 \mathrm{~m}$ above the station, and the station is at an altitude of $375 \mathrm{~m}$ a.m.s.l. (hereinafter all altitudes are mentioned above mean sea level only). The local topography is complex with a number of small hillocks around and a high hill of $\sim 1 \mathrm{~km}$ about $30 \mathrm{~km}$ from the balloon launching site in the northeast direction.

\subsection{Background weather conditions}

Over the Indian subcontinent, mesoscale phenomena including convection dominate. On the basis of the meteorological conditions over the observational site, the months are grouped into four seasons, namely, winter 


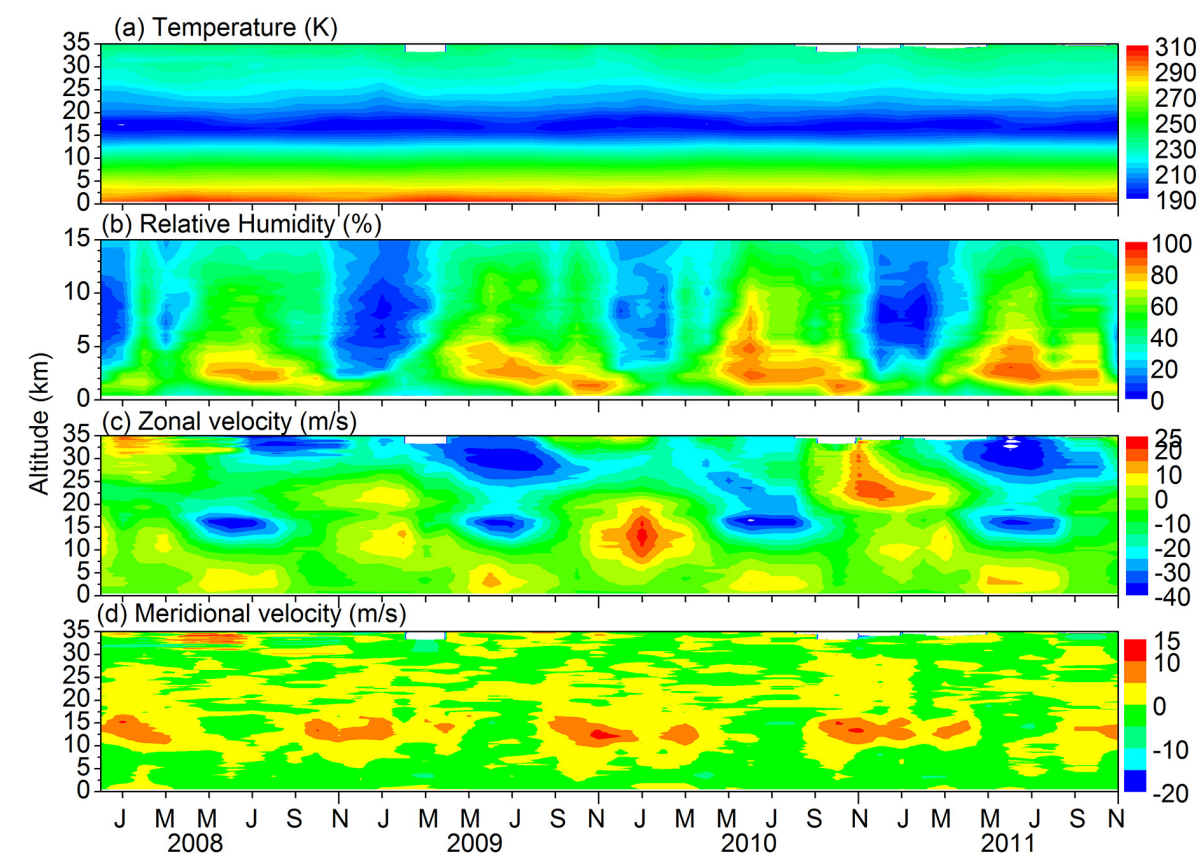

Fig. 2. Time-altitude section of monthly mean (a) $T$, (b) RH, (c) $U$ and (d) $V$ observed over Gadanki using GPS radiosonde observations during January 2008 to December 2011 using balloon ascent data.

(December-February), summer/pre-monsoon (MarchMay), monsoon/progressing southwest (SW) monsoon (June-August), and post-monsoon/retreating SW monsoon (September-November). The onset of the SW monsoon will be in the first or second week of June and withdrawal in the last week of September. Besides this, the northeast (NE) monsoon due to northeast circulation occurs over the southern part of India. Normal date of onset of the NE monsoon is in the middle of October, with a deviation of about a week on either side.

\subsection{Background meteorological conditions obtained during the balloon ascent}

In this sub-section background meteorological conditions prevailing over the observational site are briefly described based on the data collected during the balloon ascent. The monthly mean contours of the $T$, $\mathrm{RH}$, zonal $(U)$ and meridional $(V)$ winds are shown in Fig. 2a-d.

The mean zonal velocities are generally westerly during winter (with a maximum velocity of $10-12 \mathrm{~m} \mathrm{~s}^{-1}$ ) and premonsoon (up to $14 \mathrm{~km}$ with maximum velocity of $13 \mathrm{~m} \mathrm{~s}^{-1}$ ). There seem to be weak easterlies above the altitude of $14 \mathrm{~km}$ during the pre-monsoon. During the monsoon season lowlevel westerlies exist below $7-8 \mathrm{~km}$ and easterlies above. The tropical easterly jet (TEJ) is prevalent over this region in the SW monsoon season, with peak velocity sometimes reaching more than $40 \mathrm{~m} \mathrm{~s}^{-1}$ (Roja Raman et al., 2009). There exist large vertical shears during monsoon in the zonal wind. In general, meridional velocities are very small and are southward up to $8 \mathrm{~km}$ and northward above in all the seasons, except during monsoon, with peak velocity of $5 \mathrm{~m} \mathrm{~s}^{-1}$. During the winter and monsoon, somewhat stronger southerlies and northerlies prevailed respectively between 12 and $15 \mathrm{~km}$. A clear annual oscillation can be noticed in both zonal and meridional velocities. Similar variations are also observed by the MST radar located at the same site in between 4 and $20 \mathrm{~km}$ (Ratnam et al., 2008; Basha and Ratnam, 2009; Debashis Nath et al., 2009).

Temperature does not show significant variations seasonally in the lower to the middle troposphere, but shows variations in the lower stratosphere. There exist significant seasonal variations in the RH. During winter RH is very small (about $50 \%$ ) in the first few kilometers and is almost negligible above. However, during the other seasons, particularly in the monsoon season, large RH concentrations (60-70\%) can be noticed up to middle troposphere.

\section{Results and discussion}

\subsection{Maximum horizontal drift of the radiosonde while in ascent and in descent}

Before assessing the radiosonde descent data, it is desirable to see the maximum horizontal drift of the balloons from the launch location. Monthly mean drifts of the radiosondes from Gadanki location during ascent time observed in different seasons are depicted in Fig. 3. Figure 4 shows the locations of the balloons at the maximum altitude reached for all the 

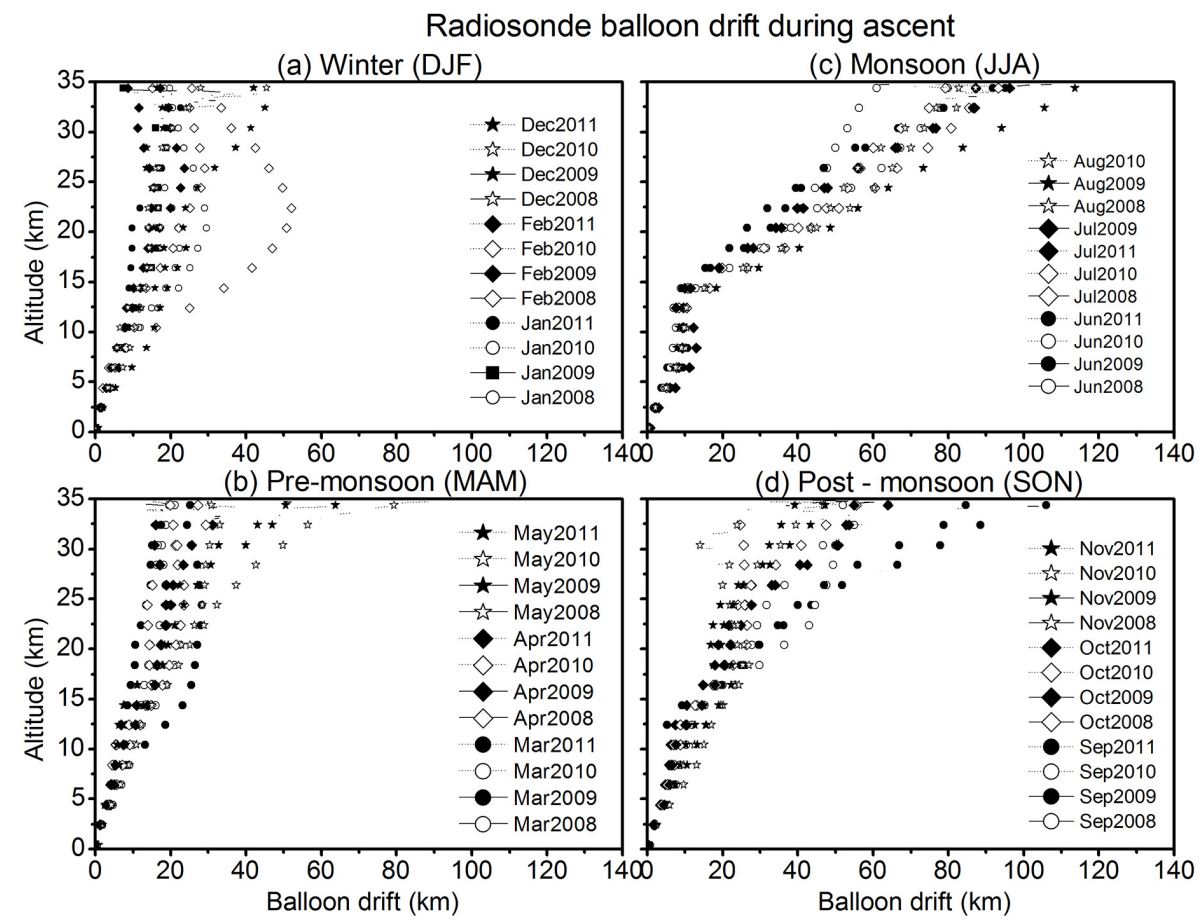

Fig. 3. Monthly mean drifts of the radiosonde from Gadanki location during ascent time observed during (a) winter, (b) pre-monsoon, (c) monsoon and (d) post-monsoon seasons.

radiosondes launched from Gadanki (shown with star mark) during January 2008 to December 2011 separated according to the season. The radiosonde balloon drift at height level zi is computed from the successively reported horizontal positions of the balloon with altitude. This is done by accumulating successive horizontal distances travelled by the balloon as given by Houchi et al. (2010):

$\operatorname{Drift}(z i)=\sqrt{\left(\sum_{j=1}^{j=t} \mathrm{~d} x_{j}\right)^{2}+\left(\sum_{j=1}^{j=t} \mathrm{~d} y_{j}\right)^{2}}$,

where $\mathrm{d} x_{j}=0.5\left(u_{j}+u_{j+1}\right) \mathrm{d} t$ and $\mathrm{d} y_{j}=0.5\left(v_{j}+v_{j+1}\right) \mathrm{d} t$ are the zonal and meridional distances travelled by the radiosonde balloon from one atmospheric level $j$ to another $j+1$ with respect to the launch location $\left(13.5^{\circ} \mathrm{N}, 79.2^{\circ} \mathrm{E}\right)$. zi is the height of the $i$ th level. In general, radiosonde has drifted maximum during the monsoon season mainly due to large winds observed due to prevailing TEJ during this season (as shown in Fig. 2). Radiosondes have gone greater than $120 \mathrm{~km}$ from the launch station during this season. The radiosonde drift in winter season is a minimum, and the maximum distance it has drifted during this season is only $20 \mathrm{~km}$. During post-monsoon and pre-monsoon seasons, the radiosonde drifts for maximum of $80-100 \mathrm{~km}$ and 40 $60 \mathrm{~km}$, respectively. The observed drifts closely match with the background wind velocities as expected (i.e., the higher the wind velocities, the larger the radiosonde drifts and vice versa). Though we cannot directly compare our results with those reported by Houchi et al. (2010) and Seidel et al. (2011) (as they have not included any Indian radiosonde observations) on the balloon drifts, note that drifts are larger at our location in contrast to those reported by them. Seidel et al. (2011) reported that drifts are larger at mid-latitudes than the tropics, but even at a tropical latitude station like Gadanki, we could notice large drifts. Another striking difference observed is that summer season drifts are larger than winter drifts unlike those reported by Seidel et al. (2011). These differences are arising mainly due to prevailing strong tropical easterly jets over the Indian region, whereas the drifts at the mid-latitudes are due to the prevailing subtropical jets (Seidel et al., 2011).

The maximum drift of the radiosondes from the balloon burst altitude and the locations of the balloons reaching the lowest altitude for all the radiosondes launched from Gadanki is also estimated for each radiosonde launched during January 2008 to December 2011 (figure not shown). It is observed that the radiosonde drifted with the background wind in descent also as expected. It is also observed that the mean drifts during descent are small in all the seasons, being less than $20 \mathrm{~km}$. Thus, in principle, it can be concluded that during the ascent and the descent similar air masses are probed. However, during disturbed weather conditions there will be large changes within $3 \mathrm{~h}$ as background will change drastically. Further, McGrath et al. (2010) reported that impact of any errors due to the mean drifts on climate statistics 

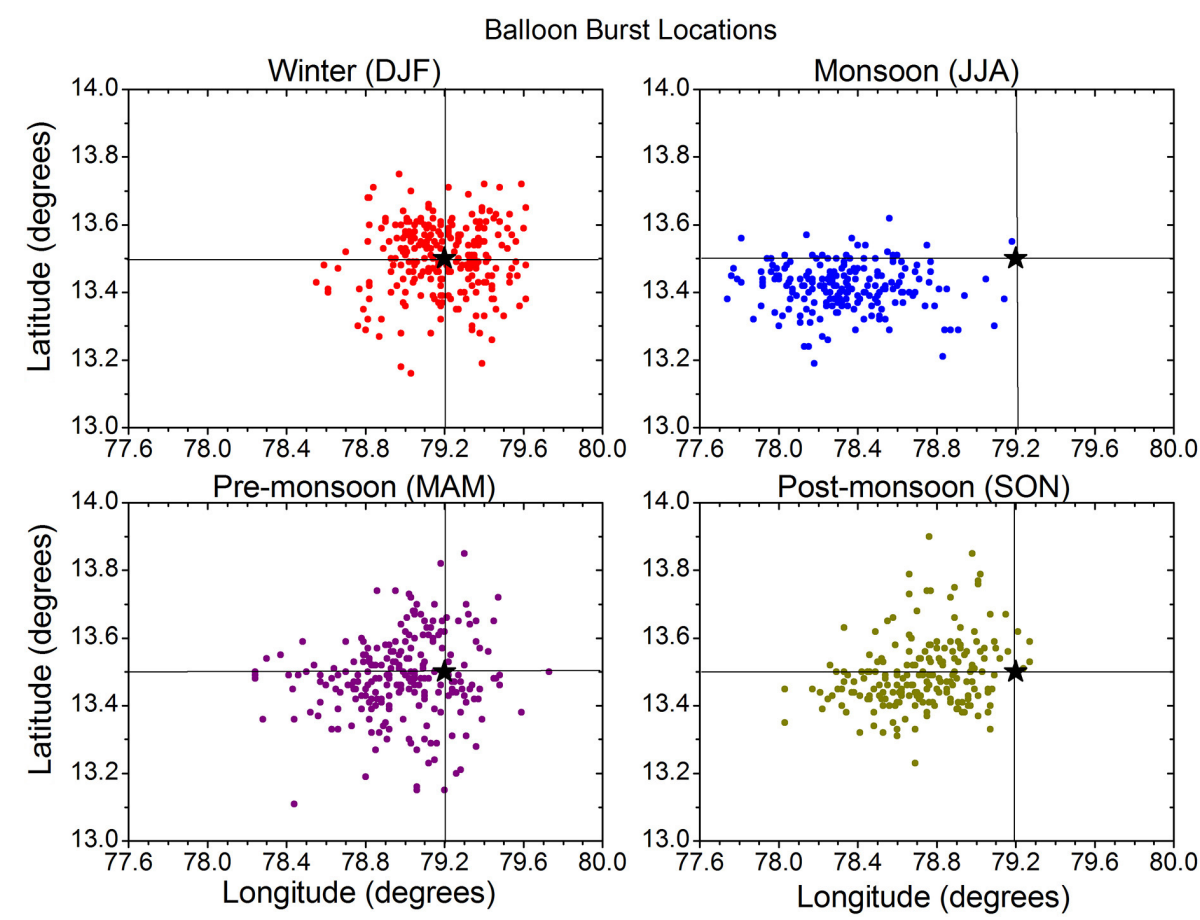

Fig. 4. The locations of the balloons reaching the maximum altitude for all the radiosonde launched from Gadanki (shown with star mark) during January 2008 to December 2011 separated according to the season.

is very small though individual errors may be of significance for weather modeling and for the tuning of satellite data (Sun et al., 2010). However, MacPherson (1995) reported that "while the impact of balloon drift can indeed be detected, it is small compared with the impact from the observation when assimilated with neglect of balloon drift". We discuss this aspect further in the following.

\subsection{Mean differences between the ascent and the descent durations}

Histograms showing the times taken for the balloon to reach maximum and minimum altitudes during different seasons along with the 4-year mean ascent and descent duration are depicted in Fig. 5. The histograms showing the ascent and descent durations reveal that it has taken about 1.5 to $2 \mathrm{~h}$ to reach maximum altitude of $30-35 \mathrm{~km}$ and mostly half an hour for the descent. There is another peak near $10 \mathrm{~min}$ suggesting that quite often it has taken less than $10 \mathrm{~min}$ to reach to the ground/near ground. Note that the total ascent duration depends on the maximum altitude reached and not all the balloons reached altitudes greater than $35 \mathrm{~km}$. However, it is very interesting to see that about $70 \%$ of the balloons had taken more than $30 \mathrm{~min}$ to reach the ground/near surface from the balloon burst altitude. The 4-year mean ascent and descent rates along with standard deviation shown in Fig. 5c reveal that the mean ascent rate is close to 5$6 \mathrm{~m} \mathrm{~s}^{-1}$ in the troposphere and reaches slightly higher values in the stratosphere, whereas the descent rate is as high as $50 \mathrm{~m} \mathrm{~s}^{-1}$ near the balloon burst altitudes and it reaches close to $10 \mathrm{~m} \mathrm{~s}^{-1}$ near the ground.

We computed the descent rate (fall velocity) using the following equation (Johansson and Bergström, 2005) based on the balance between gravity and drag forces suffered by the radiosonde (weight of $150 \mathrm{~g}$ ) (without the gas but assuming the portion of bursted balloon is still attached).

Drag $=$ mass $\times g=\frac{1}{2} \times \rho \times V_{\mathrm{T}}^{2} \times C_{\mathrm{d}} \times$ area

Terminal velocity $V_{\mathrm{T}}=\sqrt{\frac{2 \times \text { mass } \times g}{\rho \times \operatorname{area} \times C_{\mathrm{d}}}}$,

where $g$ is acceleration due to gravity, $\rho$ is the density, $C_{\mathrm{d}}$ is the drag coefficient and frontal area is calculated using both edgewise and non-edgewise. By considering the dimensions of the radiosonde as $155 \mathrm{~mm} \times 98 \mathrm{~mm} \times 88 \mathrm{~mm}$, the frontal area is calculated as $0.015 \mathrm{~m}^{2}$ (non-edgewise) or $0.008 \mathrm{~m}^{2}$ (edgewise). The 4-year mean density profile along with standard deviations used in estimating $V_{\mathrm{T}}$ is shown in Fig. $6 \mathrm{a}$. Taking $C_{\mathrm{d}}$ as 1.0 for convenience and the radiosonde mass as $150 \mathrm{~g}$, the terminal velocity is calculated both edgewise and non-edgewise and is shown in Fig. $6 \mathrm{~b}$. At $10 \mathrm{~km}$ altitude ( $\rho \sim 0.4 \mathrm{~kg} \mathrm{~m}^{-3}$ ) the terminal velocity is close to $22 \mathrm{~m} \mathrm{~s}^{-1}$ (edgewise) or $29 \mathrm{~m} \mathrm{~s}^{-1}$ (non-edgewise). At $30 \mathrm{~km}$, these values $\left(\rho\right.$ is $\sim 0.017$ ) are $106 \mathrm{~m} \mathrm{~s}^{-1}$ or $140 \mathrm{~m} \mathrm{~s}^{-1}$. The maximum observed value is $60 \mathrm{~m} \mathrm{~s}^{-1}$ (Fig. 5c) suggesting the radiosonde might be tumbling and experiencing a much higher 

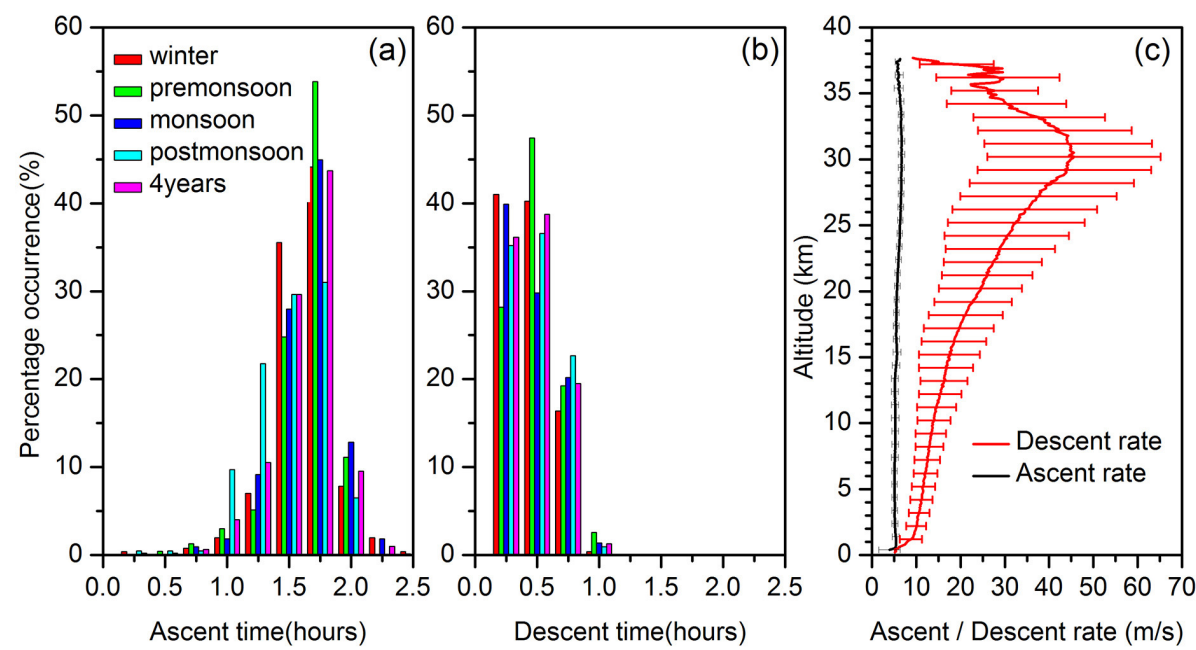

Fig. 5. Histograms showing the time taken for the balloons to reach (a) maximum and (b) minimum altitudes during different seasons along with 4-year mean ascent and descent timings. Histograms are at 15 min intervals. (c) Mean ascent and descent rates along with standard deviations obtained while averaging over 4 years.

drag. However, this can be a lower estimate due to the fact that the falling system also still contains the ruptured balloon (we have seen in few cases where we collected back fallen radiosonde) and the connecting line.

Note that the descent duration also depends on the maximum altitude (i.e., higher the maximum altitude, the longer the time taken to reach the ground). The time taken to reach different altitudes while descending from the maximum altitude is shown in Table 2. It is interesting to see no difference in the time taken to reach from $30 \mathrm{~km}$ to $10 \mathrm{~km}$ and $25 \mathrm{~km}$ to $10 \mathrm{~km}$ suggesting that radiosonde velocity is high when it bursted, which can be seen from Fig. 5c. This is also true for the balloons reaching from $30 \mathrm{~km}$ to $8 \mathrm{~km}$ and $25 \mathrm{~km}$ to $8 \mathrm{~km}$, $30 \mathrm{~km}$ to $6 \mathrm{~km}$ and $25 \mathrm{~km}$ to $6 \mathrm{~km}, 30 \mathrm{~km}$ to $4 \mathrm{~km}$ and $25 \mathrm{~km}$ to $4 \mathrm{~km}$. No marked seasonal variation in the descent times can be noticed (Table 2), and the differences are generally within the standard deviations.

\subsection{Differences between the ascent and the descent data}

As mentioned earlier, the radiosonde data are available at every 5-6 $\mathrm{m}(1 \mathrm{~s}$ interval). However, data have been smoothed to $100 \mathrm{~m}$ resolution so as to remove the errors, if any, arising due to random motion of the balloon. In a few cases we found that pressure is increasing (meaning that balloon is descending) and again ascending after a few seconds. During such cases, sudden increase in the temperature will occur. Further, $1 \mathrm{~s}$ sampling particularly at higher altitudes (lower densities) may not be sufficient to sample the background atmosphere. Thus, to avoid all these effects, we have gridded to $100 \mathrm{~m}$ resolutions for this study only, which is not necessary for other studies where higher resolution is required. Typical profiles of $T$, RH, $U, V$ (from ascent data) and ascent rate observed on 1 January 2008 at 12:00 UT are shown in Fig. 7. Since
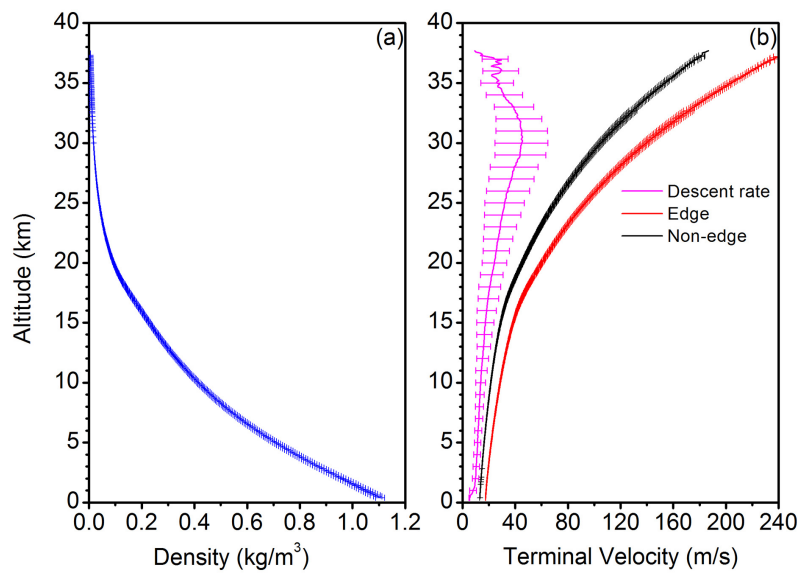

Fig. 6. (a) Mean profiles of density along with standard deviation observed over Gadanki averaged over 4 years (2008-2011). (b) Mean terminal velocity calculated for radiosonde edgewise and non-edgewise (see text for details) sections along with standard deviations. Note that mean descent rate is also superimposed for comparison.

one of the main objectives is to examine the reliability and usefulness of the descent data, the profiles of $T, \mathrm{RH}, U$, and $V$ from descent data and descent rate are also superimposed in the respective panels. Note that the descent profiles of $T$, RH, $U$ and $V$ resemble the smoothed version of the ascent profiles. In general, very good consistency can be observed between the ascent and descent data sets revealing that one more profile can be constructed within $3 \mathrm{~h}$ of time from the balloon launch.

The differences between ascent and descent data in $T, \mathrm{RH}$, $U$ and $V$ are estimated and are shown in the middle panels of Fig. 7. Note that the horizontal winds, $T$ and $\mathrm{RH}$ are 
Table 2. The mean time (hours) along with standard deviation taken for the balloons to reach from maximum altitude to the minimum altitudes during different seasons along with 4-year mean descent timings.

\begin{tabular}{lccccc}
\hline Altitude & Winter & Pre-monsoon & Monsoon & Post-monsoon & 4 years \\
\hline 30 to $10 \mathrm{~km}$ & $0.21 \pm 0.05$ & $0.22 \pm 0.05$ & $0.27 \pm 0.08$ & $0.24 \pm 0.06$ & $0.23 \pm 0.06$ \\
25 to $10 \mathrm{~km}$ & $0.21 \pm 0.07$ & $0.21 \pm 0.06$ & $0.26 \pm 0.08$ & $0.24 \pm 0.1$ & $0.22 \pm 0.07$ \\
20 to $10 \mathrm{~km}$ & $0.16 \pm 0.05$ & $0.17 \pm 0.06$ & $0.21 \pm 0.07$ & $0.2 \pm 0.09$ & $0.18 \pm 0.07$ \\
15 to $10 \mathrm{~km}$ & $0.09 \pm 0.02$ & $0.09 \pm 0.03$ & $0.11 \pm 0.03$ & $0.11 \pm 0.05$ & $0.10 \pm 0.03$ \\
\hline 30 to $8 \mathrm{~km}$ & $0.25 \pm 0.06$ & $0.26 \pm 0.05$ & $0.32 \pm 0.08$ & $0.28 \pm 0.06$ & $0.27 \pm 0.07$ \\
25 to $8 \mathrm{~km}$ & $0.25 \pm 0.07$ & $0.25 \pm 0.07$ & $0.31 \pm 0.09$ & $0.28 \pm 0.1$ & $0.27 \pm 0.08$ \\
20 to $8 \mathrm{~km}$ & $0.21 \pm 0.06$ & $0.21 \pm 0.07$ & $0.26 \pm 0.08$ & $0.26 \pm 0.12$ & $0.22 \pm 0.07$ \\
15 to $8 \mathrm{~km}$ & $0.13 \pm 0.03$ & $0.14 \pm 0.04$ & $0.16 \pm 0.04$ & $0.17 \pm 0.08$ & $0.14 \pm 0.04$ \\
\hline 30 to $6 \mathrm{~km}$ & $0.29 \pm 0.06$ & $0.3 \pm 0.05$ & $0.35 \pm 0.08$ & $0.33 \pm 0.07$ & $0.31 \pm 0.07$ \\
25 to $6 \mathrm{~km}$ & $0.3 \pm 0.08$ & $0.29 \pm 0.07$ & $0.35 \pm 0.09$ & $0.33 \pm 0.1$ & $0.31 \pm 0.08$ \\
20 to $6 \mathrm{~km}$ & $0.25 \pm 0.07$ & $0.25 \pm 0.07$ & $0.31 \pm 0.09$ & $0.29 \pm 0.1$ & $0.27 \pm 0.08$ \\
15 to $6 \mathrm{~km}$ & $0.18 \pm 0.04$ & $0.18 \pm 0.04$ & $0.2 \pm 0.05$ & $0.2 \pm 0.06$ & $0.19 \pm 0.05$ \\
\hline 30 to $4 \mathrm{~km}$ & $0.34 \pm 0.06$ & $0.35 \pm 0.06$ & $0.38 \pm 0.07$ & $0.38 \pm 0.07$ & $0.35 \pm 0.07$ \\
25 to $4 \mathrm{~km}$ & $0.35 \pm 0.09$ & $0.34 \pm 0.08$ & $0.4 \pm 0.1$ & $0.39 \pm 0.11$ & $0.36 \pm 0.09$ \\
20 to $4 \mathrm{~km}$ & $0.3 \pm 0.08$ & $0.3 \pm 0.08$ & $0.36 \pm 0.1$ & $0.35 \pm 0.11$ & $0.32 \pm 0.09$ \\
15 to $4 \mathrm{~km}$ & $0.23 \pm 0.05$ & $0.23 \pm 0.05$ & $0.26 \pm 0.06$ & $0.26 \pm 0.07$ & $0.24 \pm 0.06$ \\
\hline
\end{tabular}

(a)
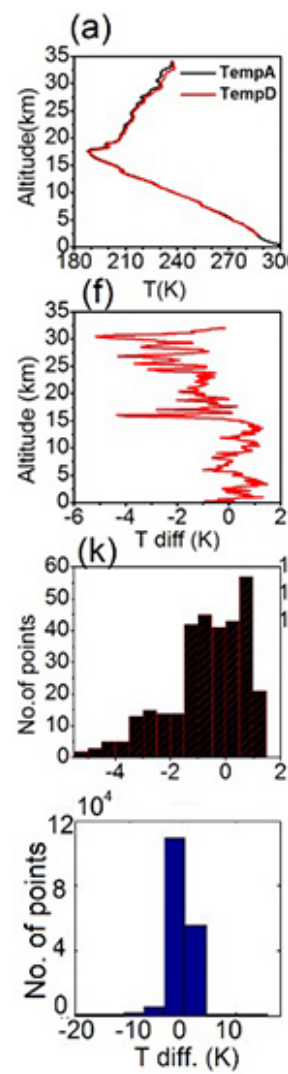

(b)

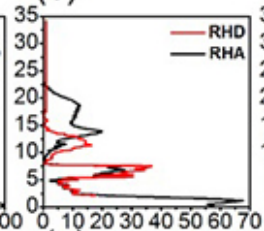

(g) $\mathrm{RH}(\%)$

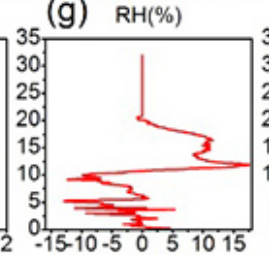

- $10-50051015$

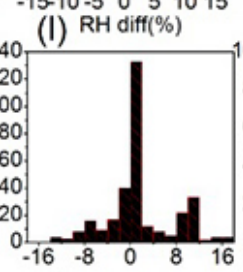

(c)

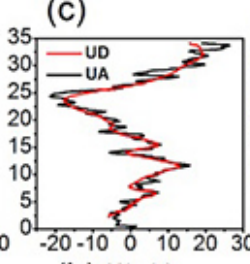

(h) $U(\mathrm{~m} / \mathrm{s})$

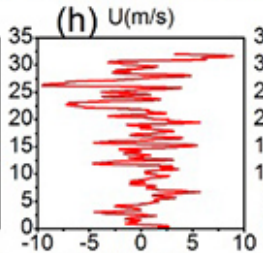

(m) $\mathrm{U}$ diff $(\mathrm{m} / \mathrm{s})$ (d)

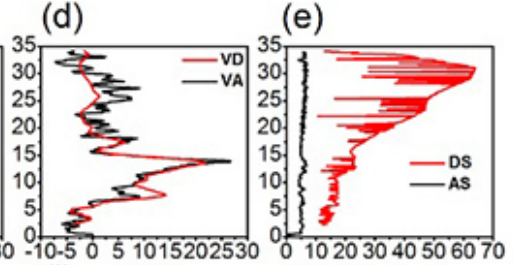

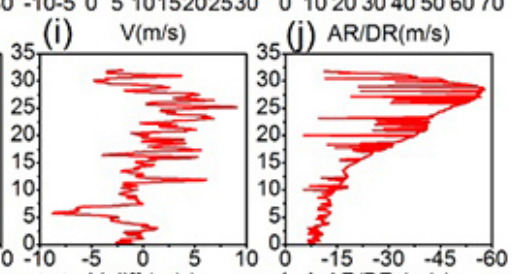

(n) $\vee \operatorname{diff}(\mathrm{m} / \mathrm{s})$
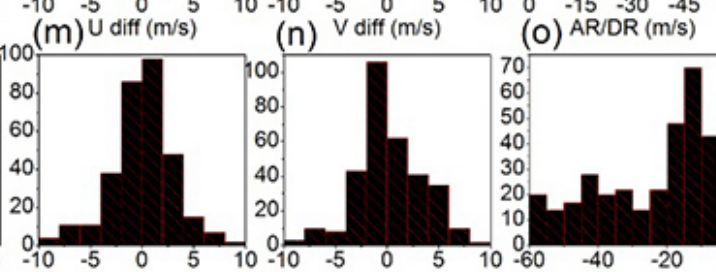

(O) AR/DR (m/s)
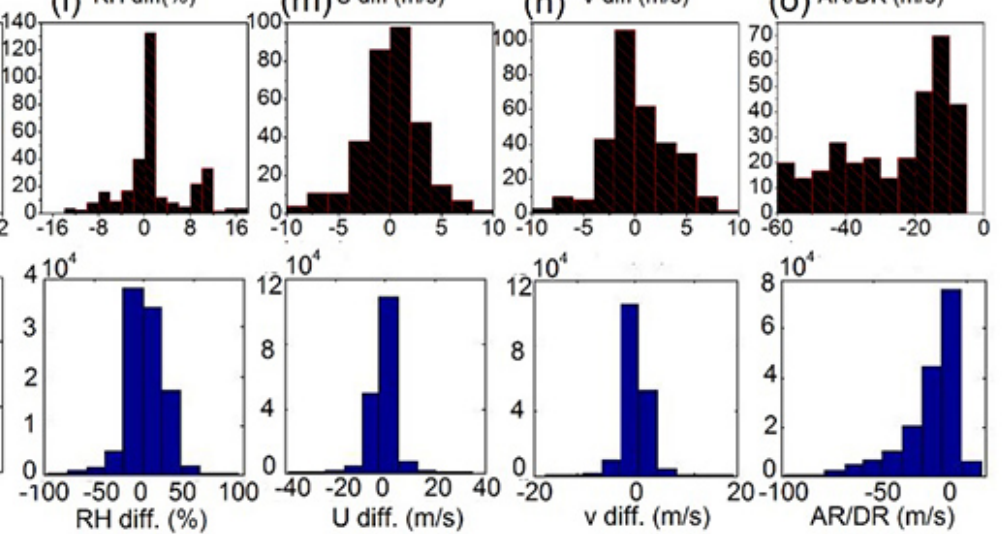

Fig. 7. First row: typical profiles of $T$, RH, $U, V$, and ascent rate observed on 1 January 2008 at 12:00 UT at Gadanki. The profiles obtained during descent are also superimposed in respective panels. Second row: the difference observed in $T, \mathrm{RH}, U, V$, and ascent rate and descent rate between ascent and descent phase. Third row: histograms showing the variability in the difference of $T, \mathrm{RH}, U, V$, and ascent rate between ascent and descent profiles. Fourth row: same as third row but for the complete 4-year period (January 2008 to December 2011). 


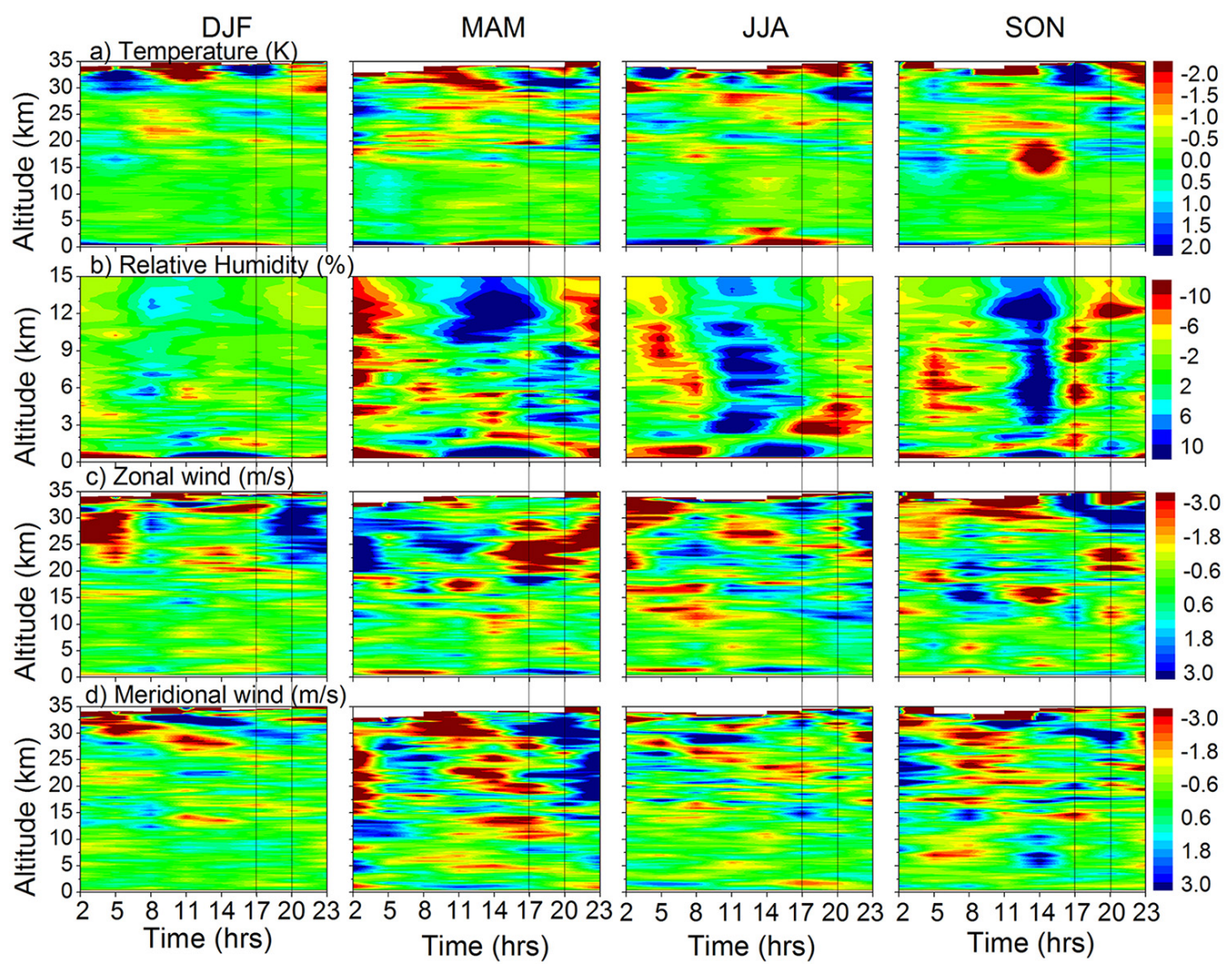

Fig. 8. Diurnal variation observed seasonally during December 2010 to May 2012 in (a) $T$, (b) RH, (c) $U$, and (d) $V$ using radiosonde ascent data. The vertical lines are drawn at 17:00 LT and 20:00 LT to highlight the variability during ascent and descent times.

measured with an accuracy of $0.15 \mathrm{~m} \mathrm{~s}^{-1}, 0.5 \mathrm{~K}$ and $5 \%$, respectively. The difference in $T$ between ascent and descent is within $1 \mathrm{~K}$ up to $\sim 16 \mathrm{~km}$ ( $\sim$ tropopause), and above the tropopause it is more and can reach as high as $4 \mathrm{~K}$. In the case of RH, there is a difference of about $10 \%$ between the ascent and descent data with higher RH during descent phase below $10 \mathrm{~km}$ and reverse above that altitude. The difference in $U$ between ascent and descent is within $4 \mathrm{~m} \mathrm{~s}^{-1}$ with slightly higher values in the lower stratosphere. Below $15 \mathrm{~km}, V$ during the descent is more and reverses above. Generally ascent rate is close to $5 \mathrm{~m} \mathrm{~s}^{-1}$. The descent rate initially is as high as $60 \mathrm{~m} \mathrm{~s}^{-1}$ and drastically decreases with increase of density to almost $10 \mathrm{~m} \mathrm{~s}^{-1}$ before it reaches the ground. Wild fluctuations in descent rate can be noticed, which probably can be attributed to tumbling of the radiosonde as indicated by the estimated terminal velocities with two different radiosonde frontal areas. The terminal velocity is inversely proportional to the square root of the frontal area. Roughly the frontal area is about one-third edgewise, so that the terminal speed would be 1.7 times the non-edgewise descent. This appears to be consistent with top two rows of Fig. 7e panels. In order to check the variability of the differences in $T, \mathrm{RH}, U$, and $V$ and between the ascent and descent rates, these are shown as histograms in the third row panels of Fig. 7. In general, most of the differences in $T$, RH, $U, V$, and ascent and descent rate are within $2 \mathrm{~K}, 5 \%, 2 \mathrm{~m} \mathrm{~s}^{-1}, 2 \mathrm{~m} \mathrm{~s}^{-1}$, and $20 \mathrm{~m} \mathrm{~s}^{-1}$, respectively.

A similar analysis as mentioned above has been done for the entire 4 years of data and is shown in the bottom panels of Fig. 7. Large spread in each of the parameters mentioned above is noticed, which can be mainly attributed to the dayto-day, seasonal, annual and inter-annual variability in the respective parameters. Relatively less variability is seen in $T$ than in RH, $U$ and $V$. The difference in $T$ is within $3 \mathrm{~K}$ up to $16 \mathrm{~km}$ and increases to $5 \mathrm{~K}$ sometimes. In case of $\mathrm{RH}$, there is a difference of about $30-40 \%$ between the ascent and the descent data with higher $\mathrm{RH}$ during the descent phase below $10 \mathrm{~km}$. The difference in $U$ between the ascent and the descent is seen up to $5 \mathrm{~m} \mathrm{~s}^{-1}$, which increases to $10 \mathrm{~m} \mathrm{~s}^{-1}$ in the lower stratosphere. The difference in $V$ goes as high as $10 \mathrm{~m} \mathrm{~s}^{-1}$ between the ascent and the descent data. The descent rate is as high as $100 \mathrm{~m} \mathrm{~s}^{-1}$ drastically decreasing with increase of density below to almost $10 \mathrm{~m} \mathrm{~s}^{-1}$ before it reaches the ground. In general, most of the differences in $T$, $\mathrm{RH}, U, V$, and ascent and descent rate are within $5 \mathrm{~K}, 30 \%$, $5 \mathrm{~m} \mathrm{~s}^{-1}, 5 \mathrm{~m} \mathrm{~s}^{-1}$, and $10 \mathrm{~m} \mathrm{~s}^{-1}$, respectively. Note that the observed differences seem to be on the higher side and are mainly arising due to including the differences immediate 

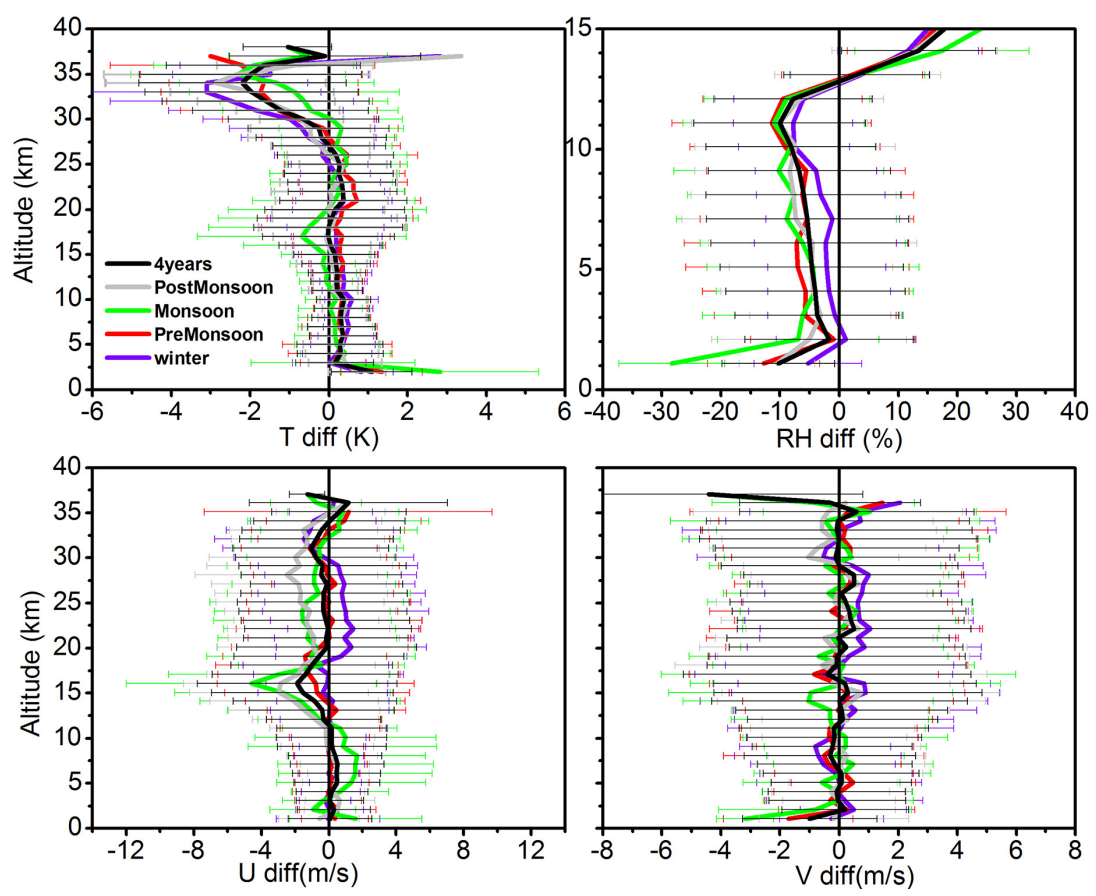

Fig. 9. Mean difference in $T$, RH, $U$ and $V$ between ascent and descent times observed during different seasons along with 4-year mean difference. Horizontal bars represent the standard deviation.

after balloon burst. Otherwise the differences will be low (details shown in Fig. 9). However, there could be several reasons for these differences within $3 \mathrm{~h}$ of observations including the diurnal variation and prevailing waves, which are discussed in detail in the following sub-sections.

\subsection{Seasonal mean differences in the meteorological parameters between the ascent and the descent data}

As there is a time difference of 2.5 to $3 \mathrm{~h}$ between the ascent and descent profiles, it is quite natural to expect some difference between these profiles because of diurnal variation of the parameter itself. To get a clear picture of the diurnal variation in each parameter, we make use of the 3-hourly radiosonde launchings done during the Tropical Tropopause Dynamics (TTD) campaign (Venkat Ratnam et al., 2014) conducted at Gadanki every month for 3 days (total 24 launches) since December 2010. The diurnal variation observed in $T$, RH, $U$ and $V$ during the above-mentioned period separated seasonally is shown in Fig. 8. The diurnal variation in $T$ below the tropopause is less than $1 \mathrm{~K}$. However, strong diurnal variation in the lower stratosphere and near ground reaching as high as $3 \mathrm{~K}$ can be noticed, and there exists some seasonal dependence in the diurnal variation. Diurnal variation with warmer and colder conditions during daytime and nighttime can be clearly noticed in the lower troposphere. The diurnal variation in RH can be as high as $15 \%$ with high and low values during noon and midnight hours, respectively, in all the seasons except in winter. In winter, no strong diurnal variation can be noticed in RH. The diurnal variation observed in $U$ and $V$ is close to $2 \mathrm{~m} \mathrm{~s}^{-1}$ in the troposphere, whereas it is as high as $4 \mathrm{~m} \mathrm{~s}^{-1}$ in the lower stratosphere. The diurnal variation between 17:00 IST (ascent time) and 20:00 IST (descent time) is highlighted with vertical lines in Fig. 8. A difference of 2-3 K, 15-20\%, 3$4 \mathrm{~m} \mathrm{~s}^{-1}$ in $T$, RH and wind components, respectively, can be noticed between 17:00 IST and 20:00 IST. Note that differences in all the meteorological parameters are seen (Fig. 5) between the ascent and descent profiles. It can be seen that the differences in the above-mentioned parameters between ascent and descent are consistent with the diurnal variations strongly supporting the contention that the descent data are meaningful and reliable and can used for scientific studies.

In order to check whether there is seasonal dependence in the observed differences in the meteorological parameters between the ascent and the descent profiles, a similar procedure is followed as for the individual cases and for all 4 years of the data. Figure 9 shows the seasonal mean difference profiles of $T, \mathrm{RH}, U$ and $V$ between ascent and descent data along with standard deviations at different altitudes. The seasonal mean differences between the ascent and descent data at different altitudes are shown in Table 3 and for all 4 years of data in Table 4. It is very interesting to see that the mean difference in $T$ is less than $0.5 \mathrm{~K}$ below $30 \mathrm{~km}$ except near the tropopause altitude during monsoon season where it reaches $1 \mathrm{~K}$ with standard deviation of $2 \mathrm{~K}$. Above $30 \mathrm{~km}$ the mean difference reaches $2 \mathrm{~K}$ with standard deviation of 4-6 K. The mean RH difference between ascent and descent 
Table 3. Mean difference between ascent and descent observed in all the parameters at different altitudes in different seasons.

\begin{tabular}{|c|c|c|c|c|c|c|c|c|}
\hline \multicolumn{4}{|c|}{ Temperature (K) } & \multicolumn{5}{|c|}{ Humidity (\%) } \\
\hline Altitude & Winter & Pre-monsoon & Monsoon & Post-monsoon & Winter & Pre-monsoon & Monsoon & Post-monsoon \\
\hline $5 \mathrm{~km}$ & $0.43 \pm 0.78$ & $0.42 \pm 0.85$ & $0.16 \pm 1.03$ & $0.37 \pm 0.82$ & $-2.84 \pm 10.62$ & $-6.66 \pm 17.03$ & $-4.69 \pm 18.86$ & $-5.52 \pm 14.04$ \\
\hline $10 \mathrm{~km}$ & $0.40 \pm 0.52$ & $0.25 \pm 0.61$ & 0.040 .76 & $0.16 \pm 0.62$ & $-7.57 \pm 9.44$ & $-8.92 \pm 15.61$ & $-8.60 \pm 14.52$ & $-7.39 \pm 15.44$ \\
\hline $15 \mathrm{~km}$ & $0.16 \pm 1.07$ & $0.30 \pm 1.16$ & $-0.28 \pm 1.68$ & $-0.01 \pm 1.10$ & $15.17 \pm 8.02$ & $16.37 \pm 10.73$ & $24.18 \pm 14.52$ & $17.77 \pm 12.47$ \\
\hline $20 \mathrm{~km}$ & $0.38 \pm 1.25$ & $0.67 \pm 1.72$ & $0.12 \pm 2.04$ & $0.09 \pm 1.42$ & - & - & - & - \\
\hline $25 \mathrm{~km}$ & $-0.12 \pm 1.21$ & $0.43 \pm 1.75$ & $0.40 \pm 1.61$ & $0.04 \pm 1.03$ & - & - & - & - \\
\hline $30 \mathrm{~km}$ & $-1.71 \pm 2.24$ & $-1.18 \pm 2.43$ & $-0.44 \pm 2.21$ & $-0.91 \pm 1.26$ & - & - & - & - \\
\hline $35 \mathrm{~km}$ & $-1.34 \pm 2.38$ & $-1.78 \pm 2.28$ & $-1.80 \pm 2.51$ & $-0.49 \pm 3.17$ & - & - & - & - \\
\hline \multicolumn{4}{|c|}{$U\left(\mathrm{~m} \mathrm{~s}^{-1}\right)$} & \multicolumn{5}{|c|}{$V\left(\mathrm{~m} \mathrm{~s}^{-1}\right)$} \\
\hline Altitude & Winter & Pre-monsoon & Monsoon & Post-monsoon & Winter & Pre-monsoon & Monsoon & Post-monsoon \\
\hline $5 \mathrm{~km}$ & $0.51 \pm 1.90$ & $0.27 \pm 2.17$ & $1.29 \pm 4.47$ & $0.40 \pm 1.97$ & $0.03 \pm 2.94$ & $0.36 \pm 2.22$ & $-0.66 \pm 2.61$ & $0.04 \pm 1.81$ \\
\hline $10 \mathrm{~km}$ & $0.04 \pm 2.11$ & $0.10 \pm 2.25$ & $0.97 \pm 5.46$ & $-0.15 \pm 2.79$ & $-0.26 \pm 2.80$ & $-0.27 \pm 2.84$ & $0.38 \pm 3.42$ & $-0.20 \pm 2.55$ \\
\hline $15 \mathrm{~km}$ & $-0.33 \pm 3.93$ & $-0.66 \pm 5.57$ & $-2.48 \pm 6.51$ & $-3.01 \pm 5.25$ & $0.86 \pm 4.61$ & $0.13 \pm 3.90$ & $-1.05 \pm 4.86$ & $0.73 \pm 4.80$ \\
\hline $20 \mathrm{~km}$ & $1.22 \pm 4.41$ & $-0.44 \pm 5.22$ & $-0.79 \pm 5.89$ & $-0.89 \pm 5.54$ & $0.77 \pm 4.20$ & $-0.03 \pm 3.95$ & $0.20 \pm 3.71$ & $-0.25 \pm 4.73$ \\
\hline $25 \mathrm{~km}$ & $1.00 \pm 4.69$ & $-0.02 \pm 4.83$ & $-1.26 \pm 5.45$ & $-1.74 \pm 4.95$ & $0.47 \pm 3.75$ & $0.08 \pm 3.56$ & $0.11 \pm 4.37$ & $-0.06 \pm 3.88$ \\
\hline $30 \mathrm{~km}$ & $-0.22 \pm 5.08$ & $-0.61 \pm 4.06$ & $-0.51 \pm 4.62$ & $-1.82 \pm 5.23$ & $-0.46 \pm 4.25$ & $0.20 \pm 4.07$ & $0.42 \pm 4.36$ & $-1.10 \pm 3.12$ \\
\hline $35 \mathrm{~km}$ & $0.09 \pm 2.67$ & $0.79 \pm 7.92$ & $0.70 \pm 3.74$ & $0.15 \pm 3.41$ & $0.47 \pm 3.55$ & $-0.07 \pm 4.80$ & $1.05 \pm 3.96$ & $-0.53 \pm 4.64$ \\
\hline
\end{tabular}

is less than $10 \%$ with standard deviation of $20-25 \%$ below $12 \mathrm{~km}$. It is again consistent to see higher RH during ascent time than descent time as the atmosphere cools by the time of descent. Since radiosonde is not sensitive to $\mathrm{RH}$ below $-40^{\circ} \mathrm{C}$ (Miloshevich et al., 2009, and references therein), no conclusion can be reached for altitudes above $12 \mathrm{~km}$, and they are erroneous and are removed. Differences seen above $25 \mathrm{~km}$ in $T$ must be due to inadequate sensor response during the fast descent so that the values are biased toward higher altitudes during descent. Thus, the hysteresis effect in the temperature observation is clearly observed.

The mean difference in $U$ and $V$ between ascent and descent is less than $1 \mathrm{~m} \mathrm{~s}^{-1}$ with standard deviation of about $5 \mathrm{~m} \mathrm{~s}^{-1}$. In general, the mean temperature difference in all the parameters is less in winter season compared to the other seasons. At altitudes near the balloon burst, since the descent rate is high (Fig. 5c), the response time of sensors is also important, where ambient density is low and the terminal velocity is high (Fig. 6). The sensor will lag behind the ambient value because of the finite response time.

\subsection{Consistency check for the descent data with immediate balloon ascent data}

In general, it takes 2 to $2.5 \mathrm{~h}$ to reach the maximum altitude of $35 \mathrm{~km}$ and takes only $30 \mathrm{~min}$ to reach surface or near surface. To reduce this time difference for a better comparison, we made use of the 3-hourly radiosonde launching done during TTD campaign mentioned above. Using these data we have estimated the difference between the descent data and the ascent data of immediate next radiosonde. In this case note that the time difference is less than half an hour below the tropopause altitude. The profiles of temperature obtained during TTD campaign launched every $3 \mathrm{~h}$ during 28-31 December 2010 are shown in Fig. 10. Descent profiles are also superimposed in the same panel. A very good consistency between the ascent and the descent profiles can be noticed. The mean difference between the ascent and the descent time along with the standard deviation shown in the same figure and Table 5 reveals a very low mean difference between the descent and the ascent profiles with maximum standard deviation of $2 \mathrm{~K}$. Details of differences between the descent and the immediate ascent data for individual profiles are shown in Table 6. Note that the standard deviations are small when compared to the ascent and the descent data of the same sounding mentioned in the last sub-section. However, from this figure it is seen that descent temperature data are lower than the immediate ascent data.

\subsection{Validation of descent data with immediate balloon ascent data: day and night differences}

It is further desirable to check the consistency in the ascent and descent data between the day and night. Here we take again TTD campaign data conducted during 21-24 July 2011 to compare the temperature difference between the descent and the immediate ascent profile during daytime and nighttime separately. Figure 11 shows profile of temperature obtained during TTD campaign launched every $3 \mathrm{~h}$ during $21-$ 24 July 2011 separately for the profiles obtained during daytime and nighttime. During daytime the temperature during the descent is observed to be less than the immediate ascent profile as expected. However, no such systematic difference during nighttime is noticed. 
Table 4. Mean difference along with standard deviation observed in all the parameters between ascent and descent at different altitudes obtained during January 2008 to December 2011.

\begin{tabular}{lrrrr}
\hline 4 years & $T(\mathrm{~K})$ & $\mathrm{RH}(\%)$ & $U\left(\mathrm{~m} \mathrm{~s}^{-1}\right)$ & $V\left(\mathrm{~m} \mathrm{~s}^{-1}\right)$ \\
\hline $5 \mathrm{~km}$ & $0.37 \pm 0.86$ & $-4.98 \pm 15.15$ & $0.54 \pm 2.62$ & $0.01 \pm 2.44$ \\
$10 \mathrm{~km}$ & $0.23 \pm 0.63$ & $-8.12 \pm 13.90$ & $0.20 \pm 3.24$ & $-0.12 \pm 2.89$ \\
$15 \mathrm{~km}$ & $0.07 \pm 1.26$ & $18.00 \pm 11.88$ & $-1.51 \pm 5.44$ & $0.22 \pm 4.56$ \\
$20 \mathrm{~km}$ & $0.35 \pm 1.64$ & - & $-0.13 \pm 5.29$ & $0.21 \pm 4.14$ \\
$25 \mathrm{~km}$ & $0.18 \pm 1.47$ & - & $-0.28 \pm 5.05$ & $0.18 \pm 3.86$ \\
$30 \mathrm{~km}$ & $-1.13 \pm 2.20$ & - & $-0.68 \pm 4.72$ & $-0.17 \pm 4.07$ \\
$35 \mathrm{~km}$ & $-1.45 \pm 2.59$ & - & $0.47 \pm 4.08$ & $0.49 \pm 4.07$ \\
\hline
\end{tabular}

Table 5. Mean difference (descent-ascent) in temperature between descent profiles and immediate ascent profiles observed during 2831 December 2010.

\begin{tabular}{lr}
\hline Altitude region & Difference in $T$ \\
\hline $1-5 \mathrm{~km}$ & $-1.12 \pm 0.29$ \\
$5-10 \mathrm{~km}$ & $-0.99 \pm 0.21$ \\
$10-15 \mathrm{~km}$ & $-0.81 \pm 0.14$ \\
$15-20 \mathrm{~km}$ & $-1.04 \pm 0.41$ \\
$20-25 \mathrm{~km}$ & $-0.62 \pm 0.39$ \\
$25-30 \mathrm{~km}$ & $-0.34 \pm 0.50$ \\
$30-35 \mathrm{~km}$ & $1.73 \pm 0.70$ \\
\hline
\end{tabular}

Table 6. Mean temperature difference between descent profile and immediate ascent profile below and above the tropopause altitude.

\begin{tabular}{lrr}
\hline Date & $0-18 \mathrm{~km}$ & $\begin{array}{r}\text { 18-maximum } \\
\text { latitude }\end{array}$ \\
\hline 28 Dec 2010, 11:00 LT & $-1.42 \pm 1.24$ & $-0.51 \pm 1.75$ \\
28 Dec 2010, 14:00 LT & $-0.66 \pm 1.18$ & $-1.44 \pm 1.12$ \\
28 Dec 2010, 20:00 LT & $-0.01 \pm 1.04$ & $-0.94 \pm 1.54$ \\
29 Dec 2010, 08:00 LT & - & $2.2 \pm 0$ \\
29 Dec 2010, 11:00 LT & $-1.23 \pm 1.09$ & $-0.24 \pm 1.19$ \\
29 Dec 2010, 14:00 LT & $-2.07 \pm 0.84$ & $-1.16 \pm 1.34$ \\
29 Dec 2010, 17:00 LT & $-0.30 \pm 0.90$ & $-0.13 \pm 1.37$ \\
29 Dec 2010, 20:00 LT & $-0.23 \pm 0.65$ & $-0.05 \pm 1.18$ \\
30 Dec 2010, 02:00 LT & $-0.15 \pm 0.70$ & $0.53 \pm 1.09$ \\
30 Dec 2010, 05:00 LT & $-0.74 \pm 0.89$ & $-0.65 \pm 1.49$ \\
30 Dec 2010, 08:00 LT & $-2.52 \pm 0.80$ & $-0.95 \pm 1.31$ \\
30 Dec 2010, 11:00 LT & $-0.82 \pm 1.09$ & $-0.72 \pm 2.13$ \\
30 Dec 2010, 14:00 LT & $-2.08 \pm 0.59$ & $-1.11 \pm 2.19$ \\
30 Dec 2010, 17:00 LT & $-0.26 \pm 0.60$ & - \\
30 Dec 2010, 20:00 LT & $-0.16 \pm 1.45$ & - \\
31 Dec 2010, 05:00 LT & $-1.51 \pm 1.00$ & $-1.59 \pm 1.47$ \\
\hline
\end{tabular}

\subsection{Background meteorological conditions constructed using descent data}

From the above, it can be concluded that descent profiles from the radiosonde observations are reliable and provide useful information similar to that of the profiles obtained

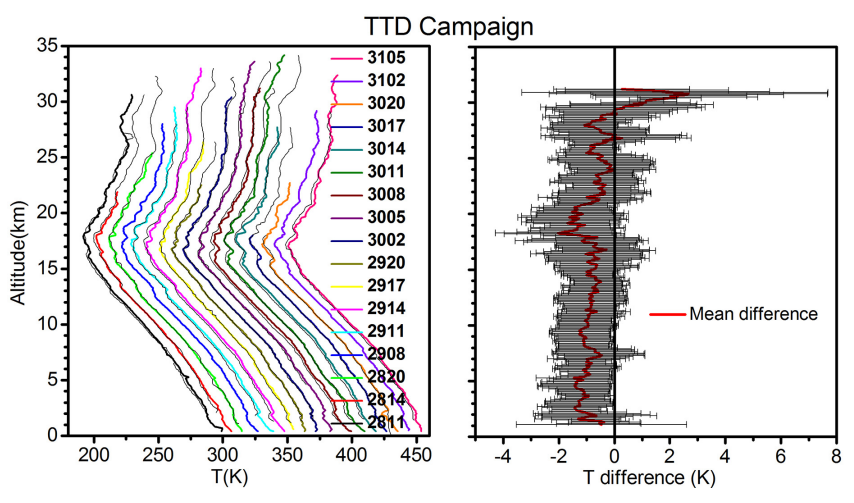

Fig. 10. Left panel: profiles of temperature obtained during Tropical Tropopause Dynamics campaign launched every $3 \mathrm{~h}$ during 28-31 December 2010. Descent profiles are also superimposed in the same panel, and subsequent profiles are shifted by $10 \mathrm{~K}$. Right panel: mean difference between descent and immediate ascent profiles along with standard deviation.

from the ascent data. The profiles of all the meteorological parameters are obtained during the descent phase for each of the ascent profiles, and the monthly mean $T, \mathrm{RH}, U$ and $V$ obtained during these descent profiles are shown in Fig. 12. The major features of the ascent data seen in Fig. 2 can be noticed in Fig. 12 as well except perhaps in RH. This may be due to slower response of RH.

\section{Summary and conclusions}

A systematic study has been made to assess the quality of the radiosonde descent data (without attaching parachute) obtained from high-resolution GPS radiosonde launched from a tropical station Gadanki during January 2008 to December 2011 for the first time. The main conclusions drawn from the present study are the following.

1. About $98.2 \%$ of the total balloons reached the altitude of tropical tropopause (around $16 \mathrm{~km}$ ), and $92.6 \%$ and $85.5 \%$ reached an altitude of greater than $20 \mathrm{~km}$ and $25 \mathrm{~km}$, respectively. The number of balloons reaching 

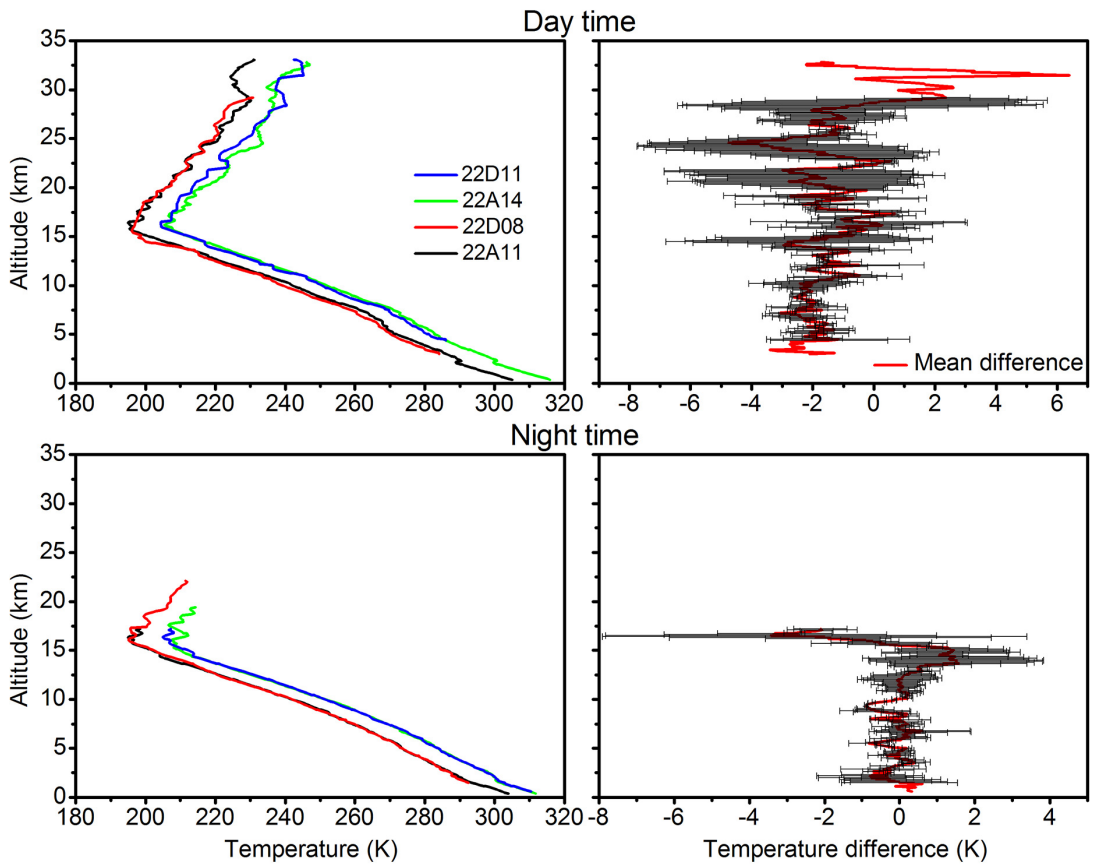

Fig. 11. Left panels: profiles of temperature obtained during Tropical Tropopause Dynamics campaign launched during daytime (top panel) and nighttime (bottom panel) every $3 \mathrm{~h}$ during 21-24 July 2011. Descent profiles are also superimposed in the same panels, and subsequent profiles are shifted by $10 \mathrm{~K}$. Ascent and descent cases are abbreviated as A and D, respectively. Right panels: mean difference between descent and immediate ascent profiles along with standard deviation.

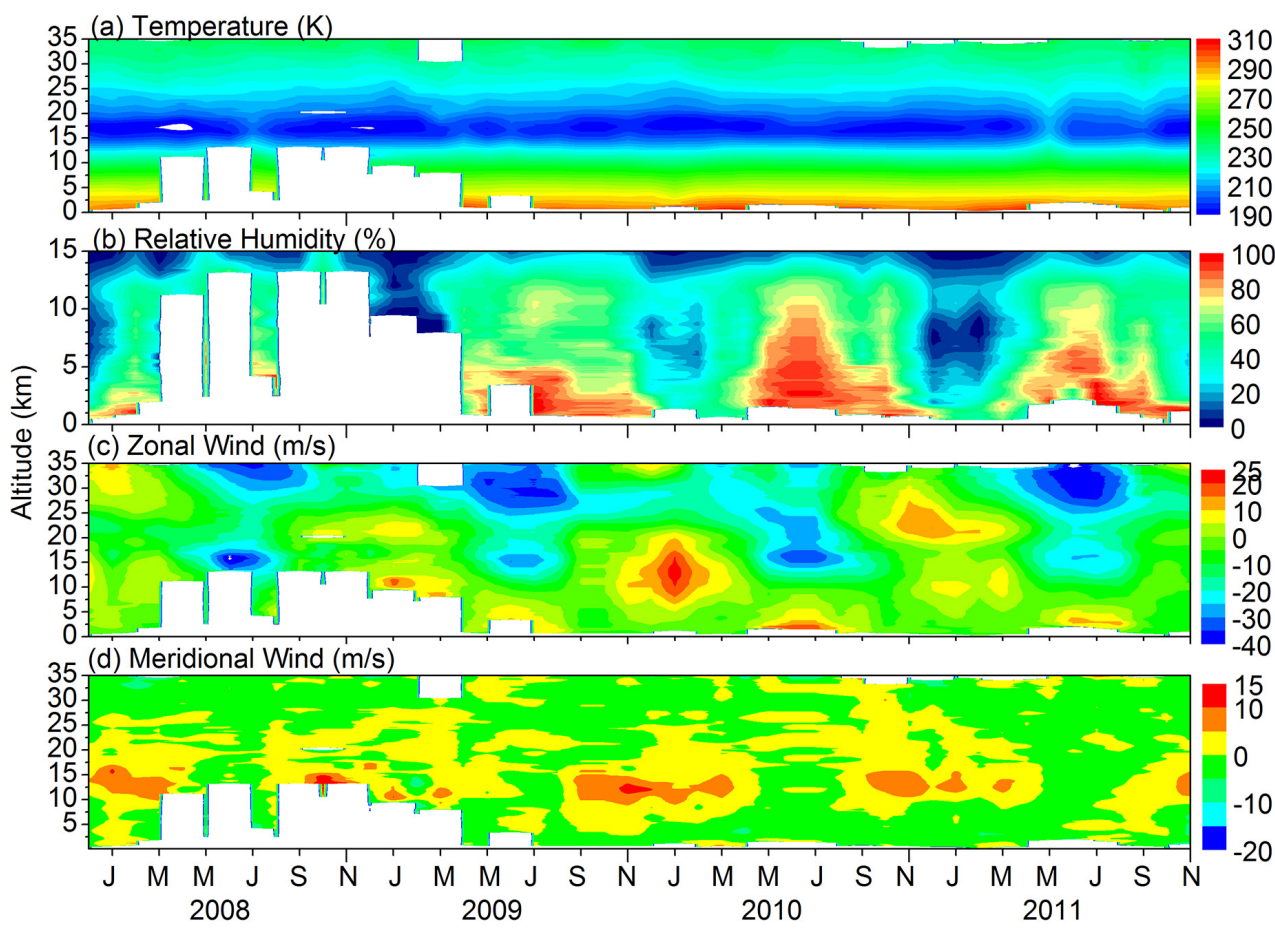

Fig. 12. Time-altitude section of monthly mean during descending (a) $T$, (b) RH, (c) $U$, and (d) $V$ observed over Gadanki using GPS radiosonde observations during January 2008 to December 2011 using balloon descent data. 
the maximum altitude is lowest in the pre-monsoon season and highest in the monsoon season.

2. More than $50 \%$ of the balloons reached (in the descent) down to $5 \mathrm{~km}$. The number of balloons reaching close to the surface $(0-1 \mathrm{~km})$ is high in the premonsoon season and the least in the monsoon season.

3. In general, radiosonde has drifted to a maximum during the monsoon season mainly due to large winds observed due to prevailing tropical easterly jet during this season. The drift in the winter season is minimum, and the maximum distance it has drifted during this season is only $20 \mathrm{~km}$. Mean drift during descent is less in all seasons (i.e., $20 \mathrm{~km}$ from balloon burst location).

4. It roughly takes 1.5 to $2 \mathrm{~h}$ to reach a maximum altitude of $30-35 \mathrm{~km}$ in the ascent. It is interesting to see that about $70 \%$ of the balloons had taken more than $30 \mathrm{~min}$ to reach the ground/near surface from the maximum altitude. This time is matching well with estimated drag and terminal velocity. As quite often it is taking more than half an hour for descent, it appears that the bursted balloon itself is acting like a kind of parachute. Moreover the descent rate while it is close to ground is only $10 \mathrm{~m} \mathrm{~s}^{-1}$ (mean is around $20 \mathrm{~m} \mathrm{~s}^{-1}$ ), which allows us to construct one more profile. Note that no parachute is attached to the balloon. The horizontal winds, $T$, and $\mathrm{RH}$ are measured with an accuracy of $0.15 \mathrm{~m} \mathrm{~s}^{-1}, 0.5 \mathrm{~K}$ and $5 \%$, respectively, during ascent. These parameters exhibit significant diurnal variation. It is very interesting to see that the mean difference in $T$ between ascent and descent is less than $0.5 \mathrm{~K}$ below $30 \mathrm{~km}$ except near the tropopause altitude during monsoon season where it reaches $1 \mathrm{~K}$ with standard deviation of $2 \mathrm{~K}$. Above $30 \mathrm{~km}$ mean difference reaches $2 \mathrm{~K}$ with standard deviation of $4-6 \mathrm{~K}$.

5. The mean RH difference between ascent and descent is less than $10 \%$ with standard deviation of 20-25\% below $12 \mathrm{~km}$. The mean difference in $U$ and $V$ between ascent and descent is less than $1 \mathrm{~m} \mathrm{~s}^{-1}$ with standard deviation of about $5 \mathrm{~m} \mathrm{~s}^{-1}$.

6. The above obtained results are further confirmed using the immediate ascent profile obtained from TTD campaign.

7. The radiosonde descent profile provides reliable data of the meteorological parameters and can be used for scientific studies.

Note that non-availability of descent data close to the ground particularly during monsoon season is not because of the technical limits of radiosonde but because of background environment. Our station is surrounded with $0.3 \mathrm{~km}$ to $0.5 \mathrm{~km}$ hills, and when the descent radiosonde happens to descend to the back of the hill, the link for data transfer will be lost. Hence, we will miss the first few kilometers during that time. However, this may not be the situation at other locations, and data can be obtained until close to the surface even during descent if no obstacle is there. Further, less difference between ascent and descent observed in this study might be due to a larger number of profiles entering the calm atmosphere. However, during disturbed weather conditions like convection or thunderstorm activity, within $3 \mathrm{~h}$ of ascent and descent time, background atmosphere will completely change; hence during those times the descent data are more useful. Thus one more reliable profile of meteorological profiles can be constructed within $3 \mathrm{~h}$ of time of balloon launch and can be used for scientific purposes. It is suggested to record the descent data whenever and wherever these type of radiosondes are launched across the globe so that one more profile of meteorological parameters can be obtained at practically no additional cost. Various studies like boundary layer processes, detection of zero degree isotherm, tropopause characteristics, turbulence (Clayson and Kantha, 2008), and estimation of instability indices using descent data will be presented in a separate communication. However, some caution is advised while using the descent data. Note that descent rate is quite high (50-60 $\mathrm{m} \mathrm{s}^{-1}$ ) immediately after balloon burst, and it takes some time to stabilize. Thus, the data within a few kilometers from the balloon burst may be biased because of improper sampling.

Acknowledgements. We wish to thank NARL staff for launching the radiosonde every day, which was the main source for the present study.

Edited by: A. Stoffelen

\section{References}

Basha, G. and Ratnam, M. V.: Identification of atmospheric boundary layer height over a tropical station using high-resolution radiosonde refractivity profiles: Comparison with GPS radio occultation measurements, J. Geophys. Res., 114, D16101, doi:10.1029/2008JD011692, 2009.

Chen, H., Zhu, Y., Zhang, J., and Xuan, Y.: Vertical air motions derived from a descending radiosonde using a lightweight hard ball as the parachute, Atmos. Meas. Tech. Discuss., 6, 8107-8127, doi:10.5194/amtd-6-8107-2013, 2013.

Clayson, C. A. and Kantha, L.: On turbulence and mixing in the free atmosphere inferred from high resolution data, J. Atmos. Oceanic Technol., 25, 833-852, doi:10.1175/2007JTECHA992.1, 2008.

Debashis Nath, Venkat Ratnam, M., Jagannadha Rao, V. V. M., Krishna Murthy, B. V., and Vijaya Bhaskara Rao, S.: Gravity wave characteristics observed over a tropical station using highresolution GPS radiosonde soundings, J. Geophys. Res., 114, D06117, doi:10.1029/2008JD011056, 2009.

Durre, I., Vose, R. S., and Wuertz, D. B.: Overview of the Integrated Global Radiosonde Archive, J. Climate, 19, 53-68, 2006. 
Houchi, K., Stoffelen, A., Marseille, G. J., and de Kloe, J.: Comparison of wind and wind-shear climatologies derived from highresolution radiosondes and the ECMWF model. J. Geophys. Res., 115, D22123, doi:10.1029/2009JD013196, 2010.

Immler, F. J., Dykema, J., Gardiner, T., Whiteman, D. N., Thorne, P. W., and Vömel, H.: Reference Quality Upper-Air Measurements: guidance for developing GRUAN data products, Atmos. Meas. Tech., 3, 1217-1231, doi:10.5194/amt-3-1217-2010, 2010.

Johansson, C. and Bergström, H.: An auxiliary tool to determine the height of the boundary layer, Bound.-Lay. Meteorol., 115, 423432, 2005.

MacPherson, B.: Radiosonde balloon drift - Does it matter for data assimilation?, Meteorol. Appl., 2, 301-305, doi:10.1002/met.5060020402, 1995.

McGrath, R., Semmler, T., Sweeney, C., and Wang, S.: Impact of balloon drift errors in radiosonde data on climate statistics, J. Climate, 19, 3430-3442, doi:10.1175/JCLI3804.1, 2006.

Miloshevich, L. M., Vömel, H., Whiteman, D. N., and Leblanc, T.: Accuracy assessment and correction of Vaisala RS92 radiosonde water vapor measurements, J. Geophys. Res., 114, D11305, doi:10.1029/2008JD011565, 2009.

Ratnam, M. V., Narendra Babu, A., Jagannadha Rao, V. V. M., Vijaya bhaskar Rao, S., and Narayana Rao, D.: Gravity wave climatology observed over a tropical station using Indian MST Radar:Source Mechanisms, J. Geophys. Res., 113, D07109, doi:10.1029/2007JD008986, 2008.
Roja Raman, M., Jagannadha Rao, V. V. M., Venkat Ratnam, M., Rajeevan, M., Rao, S. V. B, Narayana Rao, D., and Prabhakara Rao, N.: Characteristics of the Tropical Easterly Jet: Long-term trends and their features during active and break monsoon phases, J. Geophys. Res., 114, D19105, doi:10.1029/2009JD012065, 2009.

Seidel, D. J., Sun, B., Pettey, M., and Reale, A.: Global radiosonde balloon drift statistics, J. Geophys. Res., 116, D07102, doi:10.1029/2010JD014891, 2011.

Soddell, J. R., McGuffie, K., and Holland, G. J.: Inter-comparison of atmospheric soundings from the Aerosonde and Radiosonde, J. Appl. Meteor., 43, 1260-1269, 2004.

Sun, B., Reale, A., Seidel, D. J., and Hunt, D. C.: Comparing radiosonde and COSMIC atmospheric profile data to quantify differences among radiosonde types and the effects of imperfect collocation on comparison statistics, J. Geophys. Res., 115, D23104, doi:10.1029/2010JD014457, 2010.

Venkat Ratnam, M. V., Sunilkumar, S. V., Parameswaran, K., Krishna Murthy, B. V., Geetha Ramkumar, Rajeev, K., Ghouse Basha, Ravindra Babu, S., Muhsin, M., Manoj Kumar Mishra, Hemanth Kumar, A., Akhil Raj, S. T., and Pramitha, M.: Tropical Tropopause Dynamics (TTD) Campaigns over Indian region: An Overview, J. Atmos. Sol. Terr. Phys., communicated, 2014.

WMO: WMO inter-comparison of high quality radiosonde systems, Instruments and observing methods, Report No. 107, WMO/TDNo. 1580, 2011. 